\title{
Peripheral blood RNAseq links neutrophilic inflammation to clinical glioma metastasis
}

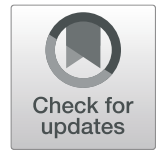

Yuanyuan Wu and Zhichao Fan ${ }^{*}$

Keywords: Gliomas, Circulating tumor cells, Neutrophils, Neutrophil extracellular traps

\section{Background}

Glioma is the most common intracranial tumor, representing about $60 \%$ of all brain tumors, and show varying degrees of malignancy [1]. Gliomas have a poor prognosis and can cause markedly high mortality. Tragically, glioblastoma (GBM), the most common glioma disease, reduces 5-year relative survival rate to $\sim 5 \%$ [2]. Thus, the mechanistic study of gliomas has vital clinical significance.

\section{CTCs and CTC clusters}

Liquid biopsies from cancer patients can enhance prognosis prediction and treatment accuracy. Many risk factors have been examined as potential contributors to glioma risk, and these studies offer new insights into the diagnostic and therapeutic strategies to suppress cancer metastasis. Analysis of circulating tumor cells (CTCs), which are highly efficient metastatic precursors, is reported to be a promising method to study the mechanisms of tumor cell dissemination and metastasis formation [3, 4]. CTCs can be found in the blood of cancer patients as single cells or as CTC clusters. While research on glioma CTCs has been slow compared with other tumor types, more attention has been paid recently. First shown to be present in GBM in 2018, CTC clusters ranging from 2 to 23 cells were present at multiple sampling time points in a GBM patient with

This comment refers to the article available at https://doi.org/10.1186/ s12916-021-02138-7.

* Correspondence: zfan@uchc.edu

Department of Immunology, School of Medicine, UConn Health, 263

Farmington Ave, Farmington, Connecticut 06030, USA pleomorphism and extensive necrosis throughout disease progression [5].

\section{hTERT helps identifying postoperative CTCs as a poor prognosis factor}

The paper presented by Zhang et al. [6] provides a more sensitive CTC measurement than the conventional CellSearch method. Their method, which is based on human telomerase reverse transcriptase (hTERT) detection, revealed new mechanisms between CTCs and innate immunity, especially pathways of neutrophil activation and neutrophil extracellular traps in gliomas. The hTRET detection method is a cell-surface marker-independent technology. It uses telomerase-specific, replicationselective oncolytic herpes simplex virus-1 to target telomerase reverse transcriptase-positive cancer cells and label them with green fluorescent protein, enabling identification of viable CTCs from a broad spectrum of malignancies [7]. Using this method, Zhang et al. found that postoperative CTCs are a poor prognosis factor, while preoperative CTCs are not, which refines our former understanding of glioma CTCs [6].

\section{RNAseq links postoperative CTCs with neutrophil inflammation}

Understanding mechanisms of metastasis not only involves CTCs but also their interactions with circulating immune cells. Another recent study used single-cell RNAseq to find that cooperation between neutrophils in the immune system and CTCs in the blood of patients with breast cancer can promote CTC proliferation and metastasis [8]. According to this new mechanism, the innate immune system may cooperate to drive tumor 
progression [9]. By analyzing RNAseq data of peripheral leukocytes in glioma patients, Zhang et al. further demonstrated that postoperative CTCs might stimulate peripheral innate immune responses by activating neutrophils and generating neutrophil extracellular traps (NETs), exhibiting increased cell cycle and DNA replication programs [6]. On the other hand, postoperative CTCs were negatively correlated with the cytotoxic response [6]. This is the first study on the correlation between macro-immunity and CTCs in glioma patients. This finding may provide new ideas for targeted systemic immunomodulatory therapy in patients with gliomas and an opportunity to reduce their spread.

\section{Conclusions}

While these studies have established the high diagnostic value of glioma CTCs, the precise detection of glioma CTCs is challenging because of physiological features such as circulation dynamics and the lack of consistently expressed tumor markers [10]. Besides, CTCs remain a limited exhibition of the metastatic process due to their dilution in patients' blood and the challenge to isolate them [5]. Therefore, omnipresent and specific markers of glioma CTCs in blood should be pursued in future research. Although neutrophil-mediated inflammatory responses correlate with postoperative CTCs and prognosis in GBM, more mechanistic studies are needed to identify potential molecular targets that reveal new insights for GBM treatment.

\section{Acknowledgements}

We acknowledge Dr. Christopher "Kit" Bonin and Dr. Geneva Hargis from UConn School of Medicine for their help with scientific writing and editing of this manuscript.

\section{Authors' contributions}

Y.W. drafted the comment. Y.W. and Z.F. edited and revised the comment. The authors read and approved the final manuscript.

\section{Funding}

This work was supported by grants from the National Institutes of Health, National Heart, Lung, and Blood Institute, USA (R01HL145454), and a startup fund from UConn Health.

Availability of data and materials

Not applicable.

\section{Declarations}

Ethics approval and consent to participate

Not applicable.

\section{Consent for publication}

Not applicable.
Received: 26 October 2021 Accepted: 26 October 2021

Published online: 03 December 2021

\section{References}

1. Pandey R, Caflisch L, Lodi A, Brenner AJ, Tiziani S. Metabolomic signature of brain cancer. Mol Carcinog. 2017;56(11):2355-71. https://doi.org/10.1002/ mc.22694.

2. Ostrom QT, Bauchet L, Davis FG, Deltour I, Fisher JL, Langer $C E$, et al. The epidemiology of glioma in adults: a "state of the science" review. Neurooncology. 2014;16(7):896-913. https://doi.org/10.1093/neuonc/nou087.

3. Aceto N, Bardia A, Miyamoto DT, Donaldson MC, Wittner BS, Spencer JA, et al. Circulating tumor cell clusters are oligoclonal precursors of breast cancer metastasis. Cell. 2014;158(5):1110-22. https://doi.org/10.1016/j.cell.2 014.07.013.

4. Piñeiro R, Martínez-Pena I, López-López R. Relevance of CTC clusters in breast cancer metastasis. Adv Exp Med Biol. 2020;1220:93-115. https://doi. org/10.1007/978-3-030-35805-1_7.

5. Krol I, Castro-Giner F, Maurer M, Gkountela S, Szczerba BM, Scherrer R, et al. Detection of circulating tumour cell clusters in human glioblastoma. $\mathrm{Br} J$ Cancer. 2018;119(4):487-91. https://doi.org/10.1038/s41416-018-0186-7.

6. Zhang W, Qin T, Yang Z, et al. Telomerase positive circulating tumor cells associated with poor prognosis via neutrophil-mediated inflammatory immune environment in glioma. BMC Med. 2021. https://doi.org/10.1186/ s12916-021-02138-7.

7. Zhang W, Bao L, Yang S, Qian Z, Dong M, Yin L, et al. Tumor-selective replication herpes simplex virus-based technology significantly improves clinical detection and prognostication of viable circulating tumor cells. Oncotarget. 2016;7(26):39768-83. https://doi.org/10.18632/oncotarget.9465.

8. Szczerba BM, Castro-Giner F, Vetter M, Krol I, Gkountela S, Landin J, et al. Neutrophils escort circulating tumour cells to enable cell cycle progression. Nature. 2019;566(7745):553-7. https://doi.org/10.1038/s41586-019-0915-y.

9. Guo B, Oliver TG. Partners in crime: neutrophil-CTC collusion in metastasis. Trends Immunol. 2019;40(7):556-9. https://doi.org/10.1016/j.it.2019.04.009.

10. Bang-Christensen SR, Pedersen RS, Pereira MA, Clausen TM, Løppke C, Sand NT, et al. Capture and detection of circulating glioma cells using the recombinant VAR2CSA malaria protein. Cells. 2019;8(9):998. https://doi.org/1 0.3390/cells8090998

\section{Publisher's Note}

Springer Nature remains neutral with regard to jurisdictional claims in published maps and institutional affiliations.
Ready to submit your research? Choose BMC and benefit from:
- fast, convenient online submission
- thorough peer review by experienced researchers in your field
- rapid publication on acceptance
- support for research data, including large and complex data types
- gold Open Access which fosters wider collaboration and increased citations
- maximum visibility for your research: over $100 \mathrm{M}$ website views per year
At $\mathrm{BMC}$, research is always in progress.
Learn more biomedcentral.com/submission 